\title{
The activation of $B D N F$ reduced inflammation in a spinal cord injury model by TrkB/p38 MAPK signaling
}

\author{
JIEDONG LIANG, GUI DENG and HE HUANG \\ Department of Orthopedics, China Three Gorges University, Yichang, Hubei 443000, P.R. China
}

Received March 30, 2018; Accepted July 20, 2018

DOI: $10.3892 /$ etm.2018.7109

\begin{abstract}
The aim of the present study was to investigate the pro-inflammation effects of brain-derived neurotrophic factor (BDNF) signaling in promoting inflammation following spinal cord injury (SCI) in rats. Reverse transcription-quantitative polymerase chain reaction was used to detect the expression of BDNF in SCI rats. The Basso, Beattie and Bresnahan (BBB) test was used and the water content of spinal cord were assessed to determine the effects of BDNF on SCI. BDNF expression was increased in SCI rats. In an in vitro model, overexpression of BDNF induced the protein expression of tyrosine kinase receptor B (TrkB) and suppressed that of phosphorylated (p-) $\mathrm{p} 38$, and reduced inflammation, as indicated by tumor necrosis factor (TNF)- $\alpha$, interleukin (IL)-1 $\beta$, IL-6, IL-18, inducible nitric oxide synthase (iNOS) and cyclooxygenase (COX)-2 levels. Conversely, the TrkB inhibitor ANA-12 suppressed the protein expression of TrkB and induced that of p-p38, and promoted inflammation (as indicated by TNF- $\alpha$, IL-1 $\beta$, IL-6, IL-18, iNOS and COX-2 levels) in an in vitro model of SCI by BDNF overexpression. In addition, the p38 inhibitor TA-0, suppressed p38 protein expression and reduced inflammation in an in vitro model of SCI by BDNF overexpression. Together, these data suggest that the pro-inflammation effects of BDNF/TrkB promoted inflammation in SCI through $\mathrm{p} 38$ signaling in rats.
\end{abstract}

\section{Introduction}

Spinal cord injury (SCI) has become a common disease with the development of modern transportation and the mining industry and affects $\sim 2.5$ million individuals worldwide (1-3). Primary SCI combined with secondary SCI seriously threatens the health and quality of life of patients (3). Primary SCI consists of irreversible tissue damages immediately following external

Correspondence to: Dr Jiedong Liang, Department of Orthopedics, China Three Gorges University, 4 Hudi Street, Yichang, Hubei 443000, P.R. China

E-mail: djlples38658@126.com

Key words: brain-derived neurotrophic factor, tyrosine kinase receptor $\mathrm{B}, \mathrm{p} 38$, spinal cord injury, inflammation forces (3). Secondary SCI refers to the cracking, progressive and self-destructive process associated with various factors, including reactive oxygen species and inflammation, based on primary injury (4). The SCI is of fundamental importance to elucidate the immunological mechanisms of secondary SCI to prevent and reverse secondary SCI (5).

A previous study on the mechanisms of post-SCI pathological injury have largely focused on primary and secondary injuries. Primary trauma of the spinal cord leads to irreversible primary injury (6). In contrast, cascade reactions of primary injury lead to reversible secondary injury, with injury levels that are even more serious than those of primary injury (7). It has previously been demonstrated that extensive nerve cell apoptosis and necrosis occur following secondary injury (8). The apoptotic nerve cells include astrocytes, microglia cells and oligodendrocytes. Furthermore, nerve cell apoptosis deconstructs the microenvironment of axon regeneration (9). A previous study has suggested that the inflammatory response triggered by secondary injury following central nerve injury is a key cause of further injury (9). Brain-derived neurotrophic factor (BDNF) is produced through proteolysis of precursor molecules (10). It is a neurotrophic factor belonging to the nerve growth factor family (10). BDNF and its receptor are extensively expressed in the nervous system (11). They are the most prevalent neurokines in vivo (12). Changes in endogenous BDNF following central lesion have been intensively studied since the discovery of BDNF (12). BDNF is a neurotrophic factor that greatly affects neuron growth and development. In addition, it can improve the physiological status of neurons under pathological status (12). BDNF has important biological roles in inflammation and apoptosis (13); therefore, it is an indispensable neurotrophic factor for maintaining normal nervous system function (14). Furthermore, BDNF is a member of the neurotrophic factor family that is mainly secreted by neuron or glial cells. It can bind with its specific receptor, tyrosine kinase receptor B (TrkB) on adjacent membranes in the paracrine or autocrine manner to exert its function (11). Furthermore, it serves a vital role in neuron survival and proliferation as well as synaptic plasticity (14). Furthermore, it can promote axonal regeneration and repair following central lesion, and accelerate limb functional recovery (14).

Receptor tropomyosin-receptor-kinase B (TrkB) plays a key role in the antidepressant functions of antidepressants (15). Blocking of BDNF-TrkB signaling inhibits the effects of neurological function recovery after treadmill training 
in spinal cord injury rat (15). BDNF-TrkB is suppressed by interleukin-1 $\beta$ via p38 mitogen-activated protein kinase (MAPK) (16). The aim of the present study was to investigate the pro-inflammation effects of BDNF signaling in promoting inflammation following spinal cord injury (SCI) in rats.

\section{Materials and methods}

Animals and surgical procedures. All animal studies were approved by the Committee of Ethics on Animal Experiments of The First People's Hospital of China Three Gorges University (Yichang, China). A total of 20 Adult male Sprague Dawley (SD) rats (weight, 250-300 g; age, 8-10 weeks) were purchased from the Animal Experiment Centre of Whuan University (Wuhan, China) and randomly assigned into the following two experimental groups: Sham-surgery group $(n=10)$ and SCI model group $(n=10)$. All SD rats were bred in China Three Gorges University at a constant temperature $\left(23 \pm 3^{\circ} \mathrm{C}\right)$, $50 \pm 5 \%$ humidity and a 12-h light/dark cycle, with free access to food and water. The sham-surgery group received sham surgery of laminectomies only. Rats were anesthetized using $35 \mathrm{mg} / \mathrm{kg}$ pentobarbital sodium (Sigma-Aldrich; Merck KGaA, Darmstadt, Germany). The T12 spinal laminectomy of the SCI model group exposed the spinal cord and an impactor with a diameter of $2.5 \mathrm{~mm}$ was used to perform a moderate-intensity weight-drop following anesthesia.

Histological preparation. All rats $(\mathrm{n}=10)$ were sacrificed via decollation under $35 \mathrm{mg} / \mathrm{kg}$ pentobarbital sodium anesthesia and spinal cord tissue samples were collected and washed with PBS. Tissue was fixed for $24-48 \mathrm{~h}$ at room temperature using $4 \%$ paraformaldehyde and dehydrated using gradient ethanol. Fixed tissue was cut into $8 \mu \mathrm{m}$-thick sagittal sections, which were stained using hematoxylin and eosin staining at room temperature for $10 \mathrm{~min}$ and examined under a confocal Eclipse 5Oi microscope (magnification, x100; Nikon Corporation, Tokyo, Japan).

Reverse transcription-quantitative polymerase chain reaction (RT-qPCR). A Trizol reagent was used to extract RNA from AGE1.HN cells following SCI induction and spinal cord tissue samples (Invitrogen; Thermo Fisher Scientific, Inc., Waltham, MA, USA). RNA was reverse transcribed into cDNA using the First Strand cDNA Synthesis kit (GeneCopoeia, Inc., Rockville, MD, USA). qPCR was performed using the ABI 7300HT real-time PCR system (Applied Biosystems; Thermo Fisher Scientific, Inc.) and the SYBR green supermix (Bio-Rad Laboratories, Inc., Hercules, CA, USA) The thermocycling conditions were as follows: $95^{\circ} \mathrm{C}$ for $10 \mathrm{~min}$, followed by 40 cycles at $95^{\circ} \mathrm{C}$ for $30 \mathrm{sec}, 58^{\circ} \mathrm{C}$ for $45 \mathrm{sec}$ and $72^{\circ} \mathrm{C}$ for $30 \mathrm{sec}$. Relative gene expression was assessed using the $2^{-\Delta \Delta \mathrm{Cq}}$ method (17).

Evaluation of Basso, Beattie and Bresnahan (BBB) test. All rats ( $n=3 /$ per group) were subjected to the $B B B$ test for the evaluation of locomotor recovery after thee induction of SCI, using a locomotor rating scale of 0 (no observable hind-limb movements) to 21 (normal locomotion). This was performed in accordance with a previous study (18).

Evaluation of the water content of spinal cord. The wet weight of spinal cord tissue samples was recorded, then spinal cord tissue samples were dried at $70-80^{\circ} \mathrm{C}$ for $48 \mathrm{~h}$ and the dry weight was recorded. Spinal cord water content (\%) was calculated as follows: (Wet weight-dry weight)/wet weight x100.

ELISA assays. All rats ( $\mathrm{n}=3)$ were sacrificed, and sensorimotor cortical tissues were removed and incubated with radioimmunprecipitation assay buffer (Beyotime Institute of Biotechnology, Haimen, China) on ice for $30 \mathrm{~min}$. Then, miscible liquids were centrifuged at $13,200 \mathrm{x} \mathrm{g}$ at $4^{\circ} \mathrm{C}$ for $10 \mathrm{~min}$. The protein concentration of soluble materials was determined using a bicinchoninic acid protein assay kit in accordance with the manufacturer's protocol (Beyotime Institute of Biotechnology). A total of $10 \mu \mathrm{g}$ protein was used to measure interleukin (IL)-1 $\beta$ (cat. no. H002), IL-6 (cat. no. H007), IL-18 (cat. no. H015), tumor necrosis factor (TNF)- $\alpha$ (cat. no. H052), inducible nitric oxide synthase (iNOS; cat. no. A014-1-1) and cyclooxygenase (COX)-2 (cat. no. H200) levels using ELISA kits (Nanjing Jiancheng Bioengineering Institute, Nanjing, China).

In vitro model and transfection. The nerve cell line AGE1.HN was purchased from the Type Culture Collection of the Chinese Academy of Sciences (Shanghai, China) and cultured in Dulbecco's modified Eagle's medium medium (Gibco; Thermo Fisher Scientific, Inc.) supplemented with $10 \%$ fetal bovine serum (Gibco; Thermo Fisher Scientific, Inc.), $100 \mathrm{U} / \mathrm{ml}$ penicillin and $100 \mu \mathrm{g} / \mathrm{ml}$ streptomycin (HyClone; GE Healthcare Life Sciences, Logan, UT, USA), and maintained at $37^{\circ} \mathrm{C}$ in a humidified atmosphere with $5 \% \mathrm{CO}_{2}$. BDNF-pcDNA3.1 (forward, 5'-AGAAAAGCCAAFFAGTGAA-3' and reverse, 5'-AAAAGGGGAAGATAGTGGATTTATGTT-3') and negative-pcDNA3.1 negative mimic plasmids (forward, 5'-CCC CCCCCCCCCCCCCCC-3' and reverse, 5'-CCCCCCCCC CCCCCCCCC-3') were constructed by Sangon Biotech Co., Ltd., (Shanghai, China). Cells were transfected with $100 \mathrm{ng}$ BDNF plasmid or negative mimics using Lipofectamine 2000 (Invitrogen; Thermo Fisher Scientific, Inc.), according to the manufacturer's protocol. Following $48 \mathrm{~h}$ transfection, cells were induced with $100 \mathrm{ng} / \mathrm{ml}$ lipopolysaccharide (LPS; Beyotime Institute of Biotechnology) for $4 \mathrm{~h}$ at $37^{\circ} \mathrm{C}$. Cells were treated with $10 \mu \mathrm{M}$ ANA-12 (MedChemExpress, Monmouth Junction, NJ, USA), a TrkB inhibitor, or $5 \mathrm{nM}$ TA-02 (MedChemExpress, Monmouth Junction, NJ, USA), a p-38 inhibitor for $44 \mathrm{~h}$ at $37^{\circ} \mathrm{C}$, and cells were inducted with $100 \mathrm{ng} / \mathrm{ml} \mathrm{LPS} \mathrm{for} 4 \mathrm{~h}$ at $37^{\circ} \mathrm{C}$, respectively and then were induced by $100 \mathrm{ng} / \mathrm{ml}$ LPS for $4 \mathrm{~h}$ at $37^{\circ} \mathrm{C}$. Negative group, cell was transfected with negative mimics.

Western blotting. Total protein was extracted from sensorimotor cortical tissues and protein concentration was determined as detailed above. Equal amounts of protein $(50 \mu \mathrm{g})$ were separated by $12 \%$ SDS-PAGE followed by transferring onto polyvinylidene difluoride membranes. Polyvinylidene difluoride membranes were blocked with $5 \%$ skimmed milk in $0.01 \%$ TBS-Tween 20 for $1 \mathrm{~h}$ at $37^{\circ} \mathrm{C}$ and then incubated with anti-BDNF (sc-20981; 1:200; Santa Cruz Biotechnology, Inc., Dallas, TX, USA), anti-phosphorylated (p)-TrkB (4619; 1:500; Cell Signaling Technology, Inc., Danvers, MA, USA), anti-p-p38 (sc-17852-R; 1:4,000; Santa Cruz Biotechnology, Inc.), and anti-GAPDH (sc-51631; 1:5,000; Santa Cruz 
A

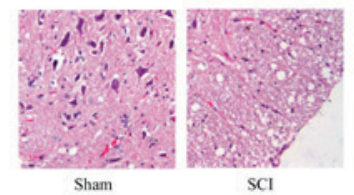

D
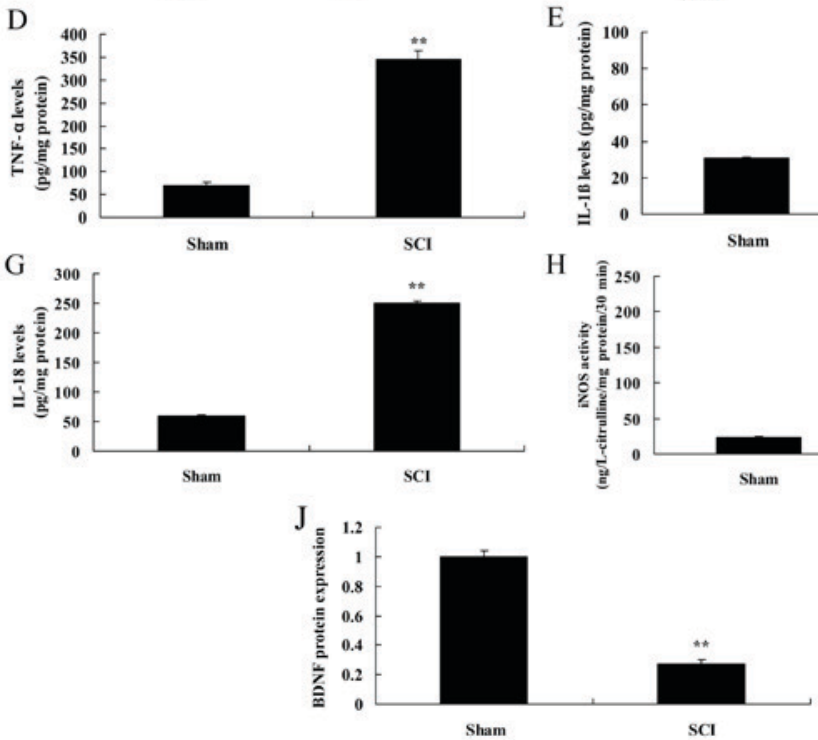

B
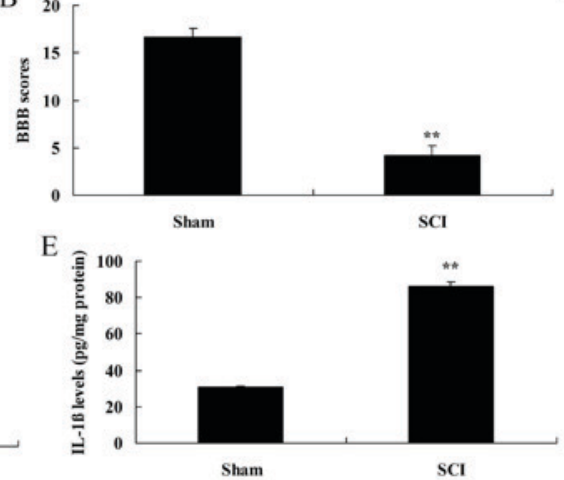

$\mathrm{H}$ 重 250

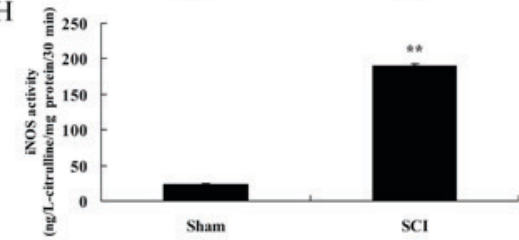

$\mathrm{C}$
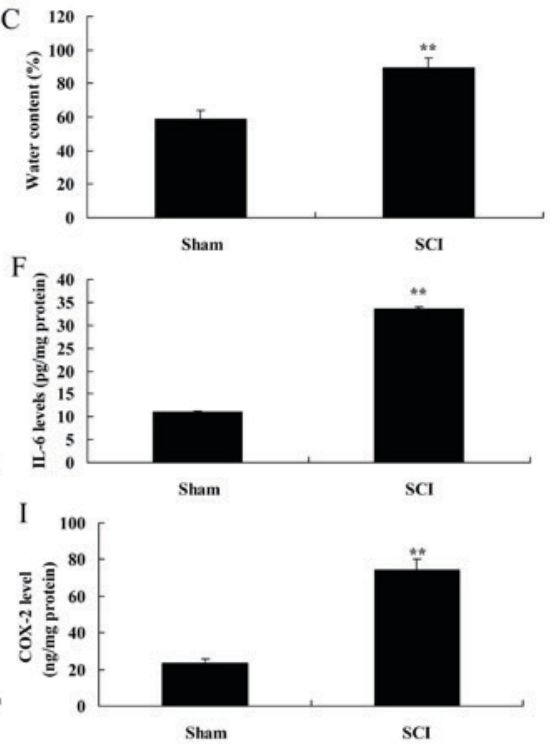

K

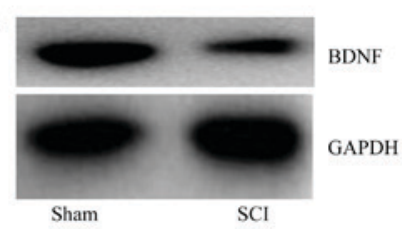

Figure 1. Expression of BDNF in SCI rats. (A) Histological evaluation (original magnification, x100). (B) BBB scores, (C) water content of spinal cord. (D) TNF- $\alpha$, (E) IL-1 $\beta$, (F) IL-6, (G) IL-18, (H) iNOS and (I) COX2 levels. (J) BDNF protein expression, as determined using statistical analysis. (K) Western blot analysis of BDNF protein expression. Data are presented as the mean \pm standard error of the mean for three independent experiments. ${ }^{* *} \mathrm{P}<0.01 \mathrm{vs}$. sham. BBB, Basso, Beattie and Bresnahan; SCI, spinal cord injury; TNF, tumor necrosis factor; IL, interleukin; iNOS, inducible nitric oxide synthase; COX, cyclooxygenase; BDNF, brain-derived neurotrophic factor.

Biotechnology, Inc.) overnight at $4^{\circ} \mathrm{C}$. Membranes were washed with TBST for 15 min and incubated with horseradish peroxidase conjugated goat anti-rabbit immunoglobulin G (cat. no. sc-2004; Santa Cruz Biotechnology, Inc.) for $1 \mathrm{~h}$ at $37^{\circ} \mathrm{C}$. Membranes were analyzed using an electrochemiluminescence (ECL) reagent and measured using Image Lab 3.0 (Bio-Rad Laboratories, Inc.).

Immunocytochemistry. Cells after the induction of SCI were washed with PBS and fixed with $4 \%$ paraformaldehyde in PBS (pH 7.4) for $15 \mathrm{~min}$ at room temperature. Cells were then blocked with 5\% bovine serum albumin (Beyotime Institute of Biotechnolgy) in PBS containing $0.5 \%$ Triton X-100 for $1 \mathrm{~h}$ at room temperature, then incubated with anti-TrkB antibody (cat. no. sc-12; 1:100; Santa Cruz Biotechnology, Inc.), anti-BDNF antibody (cat. no. sc-546; 1:100; Santa Cruz Biotechnology, Inc.) at $4^{\circ} \mathrm{C}$ overnight. Following washing for 30 min using PBS-Tween 20 (PBST), cells were incubated with goat anti-rabbit IgG-CFL 555 (cat. no. sc-362272; 1:1,000; Santa Cruz Biotechnology, Inc.) for $1.5 \mathrm{~h}$ at room temperature. Cells were then stained using a DAPI assay for $15 \mathrm{~min}$ at room temperature and washed with PBST for $30 \mathrm{~min}$ at room temperature. Cells were visualized under fluorescence microscopy (magnification, x20; Nikon Corporation).

Statistical analysis. Data are presented as the mean + standard error of the mean. Data were analyzed using Student's t-test or one-way analysis of variance followed by Tukey's test. $P<0.05$ was considered to indicate a statistically significant difference.

\section{Results}

Expression of BDNF in SCI rats. To explore the function of BDNF on inflammation in SCI rats, the expression of BDNF in SCI rats was analyzed. HE staining demonstrated that spinal cord cells seemed to be dead in SCI rats, compared with sham control group (Fig. 1A). BBB score was inhibited and water content of the spinal cord was increased in SCI rats, compared with the sham control group (Fig. 1B and C). The levels of IL-1 $\beta$, IL-6, IL-18 and TNF- $\alpha$ in SCI rats were also increased in SCI rats compared with those in sham-surgery rats (Fig. 1D-G). Additionally, iNOS and COX-2 levels were also increased in SCI rats, compared with sham control group (Fig. 1H and I). The expression of BDNF in SCI rats was further analyzed, which revealed that the expression of BDNF was reduced in SCI rats, compared with the sham control group (Fig. 1J and K). Therefore, these results demonstrated that BDNF may be associated with inflammation of SCI.

Overexpression of BDNF induces TrkB and $p-p-38$ protein expressions in vitro. Next, the exact roles of BDNF in inflammation in vitro were evaluated. As presented in Fig. 2A-D, BDNF expression plasmids significantly increased the protein expression of BDNF and TrkB, and suppressed that of p-p38 in an in vitro model, compared with the negative group. Consistently, immunofluorescence indicated that the BDNF expression plasmid markedly induced BDNF protein expression in an in vitro model, in comparison with negative group (Fig. 2E). 
A

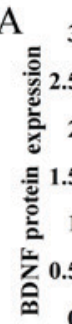

3
2.5
2
0
0.5
1
0.5
0
0
0
0.
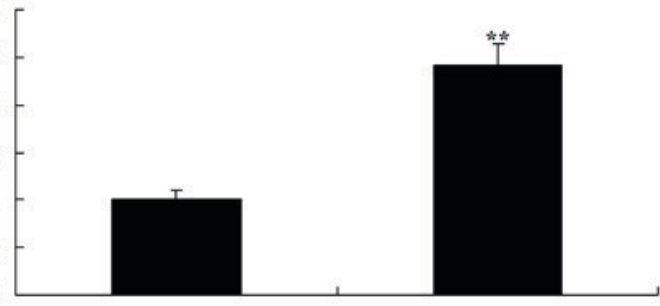

Negative

BDNF

\section{C}

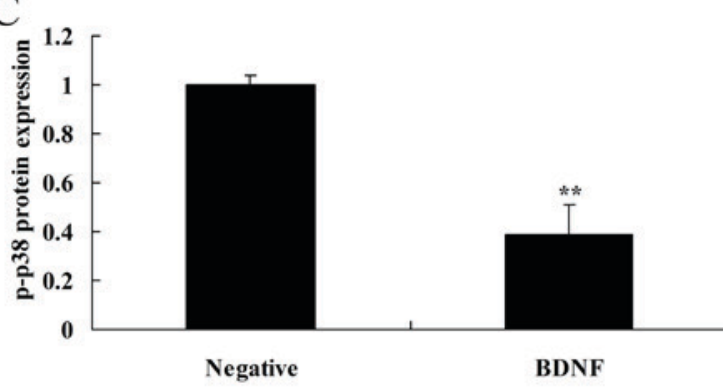

$\mathrm{E}$

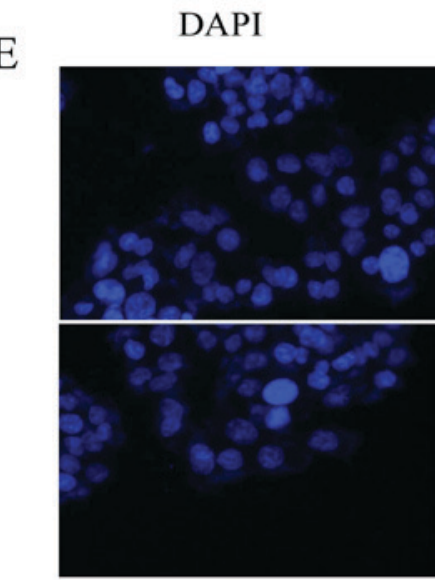

B

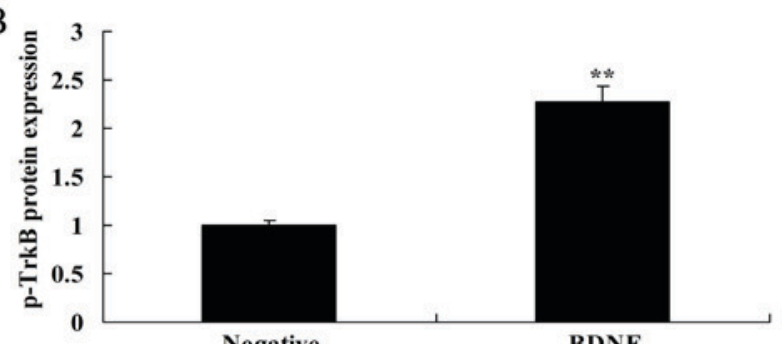

Negative

BDNF

D

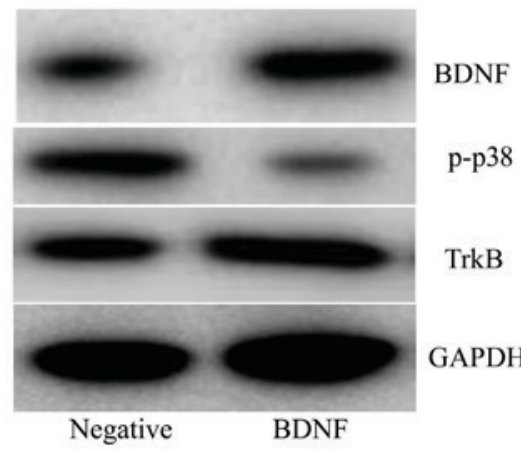

Merge
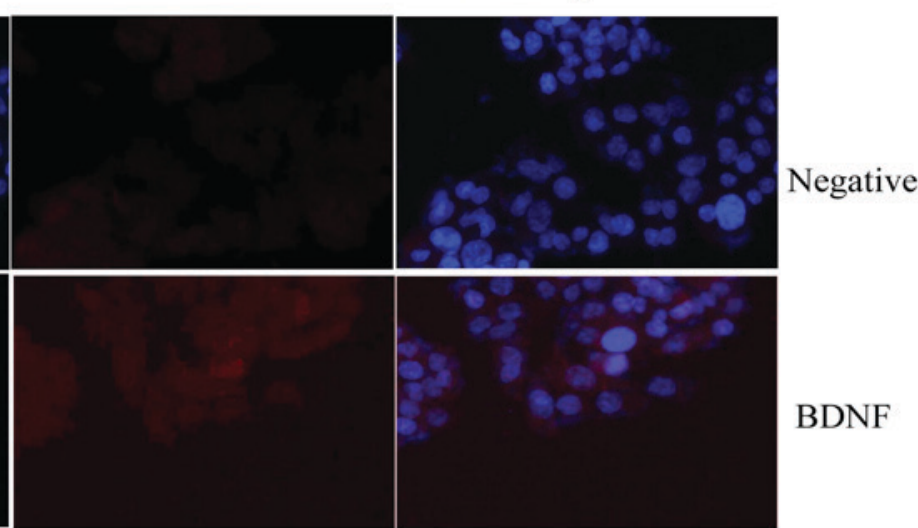

BDNF

Figure 2. Overexpression of BDNF induces TrkB and p-p-38 protein expressions in vitro. (A) BDNF, (B) p-TrkB and (C) p-p-38 protein expression, as determined using statistical analysis. (D) Western blot analysis of BDNF protein expression (E) BDNF protein expression as determined by immunocytochemistry (magnification, x100). Negative, negative mimics group; BDNF, Overexpression of BDNF group. Data are presented as the mean + standard error of the mean for three independent experiments. ${ }^{* *} \mathrm{P}<0.01$ compared withnegative group. BDNF, brain-derived neurotrophic factor; TrkB, tyrosine kinase receptor B.

Overexpression of BDNF reduces inflammation in vitro. Overexpression of BDNF reduced the levels of IL-1 $\beta$, IL-6, IL-18 and TNF- $\alpha$ in vitro, compared with the negative group (Fig. 3A-D). In addition, overexpression of BDNF decreased the levels of iNOS and COX-2 levels in vitro, compared with the negative group (Fig. 3E and F). These data indicated that BDNF reduced inflammation in SCI via the TrkB/p38 mitogen-activated protein kinase (MAPK) signaling pathway.

Inhibition of TrkB increases the anti-inflammation effects of BDNF on TrkB and p-p-38 protein expressions in vitro. The role of TrkB in the anti-inflammation effects of BDNF on inflammation in SCI was next investigated. As presented in Fig. 4, the TrkB inhibitor, ANA-12 suppressed the protein expression of TrkB, increased that of $\mathrm{p}-\mathrm{p}-38$, promoted the levels of IL-1 $\beta$, IL-6, IL-18 and TNF- $\alpha$ levels and increased those of iNOS and COX-2 in vitro of SCI by BDNF overexpression, compared with the BDNF overexpression group.
These findings suggest that overexpression of BDNF may be associated with inflammation of SCI via TrkB.

Inhibition of p38 increases the anti-inflammation effects of $B D N F$ on inflammation in vitro. Finally, the role of p38 was determined in anti-inflammation effects of BDNF on inflammation in SCI. As presented in Fig. 5, p-38 inhibitor, TA-02, suppressed p-38 protein expression, reduced IL-1 $\beta$, IL-6, IL-18 and TNF- $\alpha$ levels and inhibited iNOS and COX-2 levels in an in vitro model of SCI by BDNF overexpression, compared with the BDNF overexpression group. Therefore, these data indicated that BDNF attenuated inflammation in SCI by regulating the TrkB/p-38 pathway.

\section{Discussion}

SCI refers to serious damage of the central nervous system. In general, serious neurologic impairment may occur following SCI (19). However, motor dysfunction is a principal factor 
A
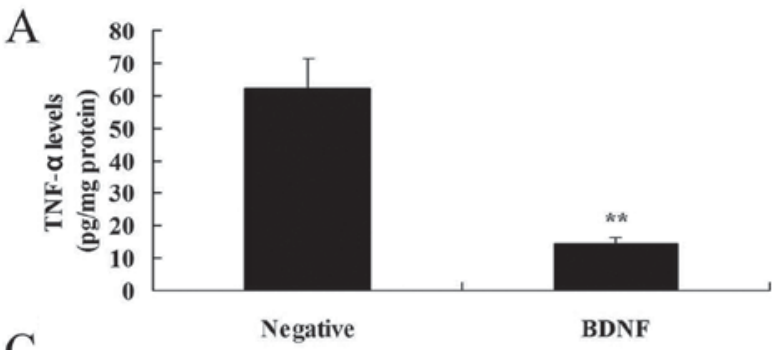

$\mathrm{C}$
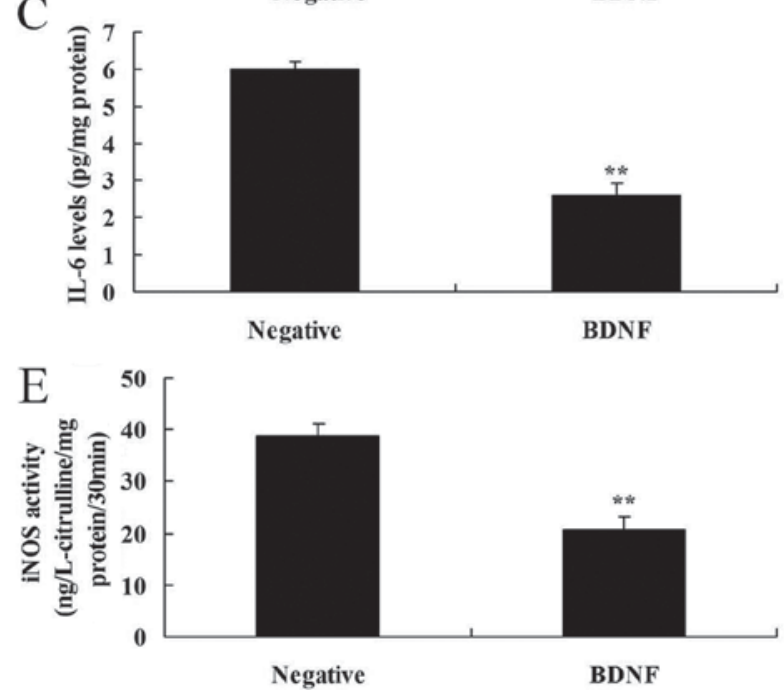

$\mathrm{B}$

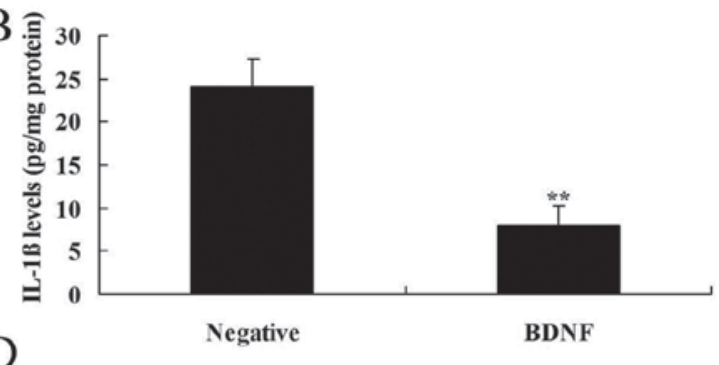

$\mathrm{D}$
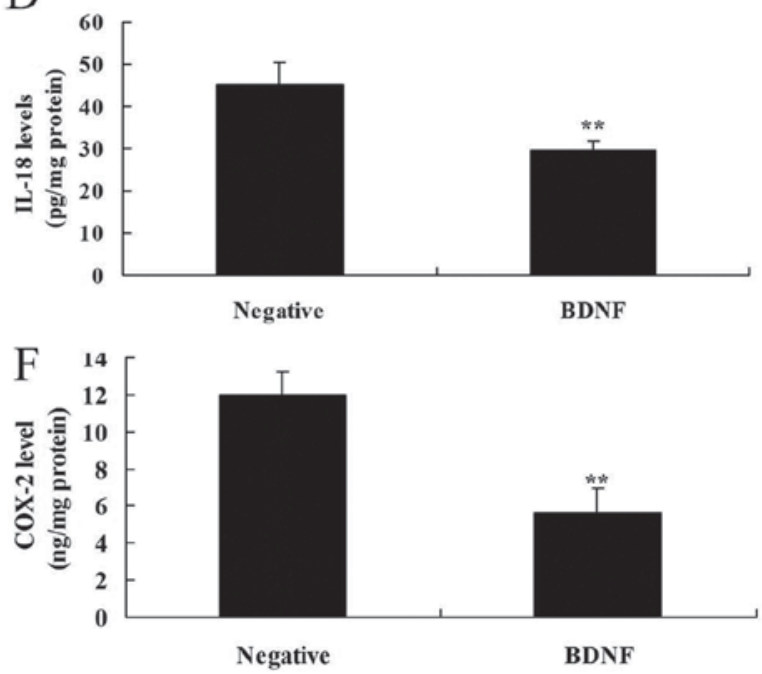

Figure 3. Overexpression of BDNF reduces inflammation in vitro. (A) TNF- $\alpha$, (B) IL-1 $\beta$, (C) IL-6, (D) IL-18, (E) iNOS and (F) COX2 levels in the negative (negative mimics) and BDNF groups Data are presented as the mean + standard error of the mean for three independent experiments. ${ }^{* *}<0.01$ compared with negative group. BDNF, brain-derived neurotrophic factor; TNF- $\alpha$, tumor necrosis factor- $\alpha$; IL, interleukin; iNOS, inducible nitric oxide synthase; COX2, cyclooxygenase-2.

leading to the loss of ability of daily activities (20). Therefore, motor dysfunction repair of SCI patients has been a focus of doctors and patients (21). However, motor function training is an important method for motor function rehabilitation (21). Previous studies have demonstrated that persistent nursing intervention at early stages can partially promote the rehabilitation of motor functions $(21,22)$. However, the underlying mechanisms have not yet been illustrated and more fundamental research is required. The results of the present study suggested that the expression of BDNF was reduced in SCI rats.

IL-1 $\beta$ and IL- 6 are cytokines with broad biological effects. Various types of cell produce IL-1 $\beta$ and IL-6, such as monocytes, B cells, T cells, fibroblasts and endothelial cells (23). IL-1 $\beta$ and IL- 6 may originate from microglial cells and astrocytes, and be secreted by neurons at early stages of SCI (24). Neurogliocytes can regulate cell growth and functions in the central nervous system and participate in the inflammatory response and immunoreaction (25). It is potentially an important factor for amplification of the inflammatory response at damage regions and secondary immune injury following primary injury (25). In the present study, it was demonstrated that overexpression of BDNF induces TrkB and $\mathrm{p}-\mathrm{p}-38$ protein expressions in vitro.

BDNF mainly functions to promote the survival of neurons and regeneration of protuberance (26). Previous studies have suggested that following SCI, expression levels of BDNF in mice would re-actively increase (26). Following SCI, the requirement of BDNF by dynamoneure is enhanced $(26,27)$.
Endogenous BDNF originates from Schwann cells and muscular tissues (28), and serves an important role in remyelination of the axon (28). Endogenous BDNF also participates in the regulation of growth-associated protein-43 (28).

Neurotrophic factors are a type of polypeptide or protein factor (29). They can promote the growth of nerve cells, survival and differentiation. Neurotrophic factors regulate the survival of neurons during neuro-development and activate enzyme activities biochemically and physiologically (27). Furthermore, they can prevent the death of neurons following injury, and promote the repair of neurons and axonal regeneration (27). Furthermore, they can also regulate nervous system functions, including plasticity of synapses and neurotransmitter transmission (25). The present study demonstrates that overexpression of BDNF reduces SCI inflammation in vitro. Chang et al (30) previously demonstrated that 7,8-DHF, produces fast-onset antidepressant-like effects in rats exposed to chronic mild stress via BDNF levels. The present results demonstrated that DHF regulates BDNF to prevent SCI in a rat model.

TrkB is expressed in neurons in the central nervous system, including the spinal cord, cerebral cortex, epencephalon and olfactory bulb (31). Following SCI, TrkB expression in a high-zinc dietary group is markedly higher than that in an appropriate zinc group (32). TrkB protein expression in a zinc deficiency group is relatively low (32). High expression of TrkB is possibly conducive to the increase of BDNF expression, which may reduce the possibility of secondary injury following acute SCI (32). In 

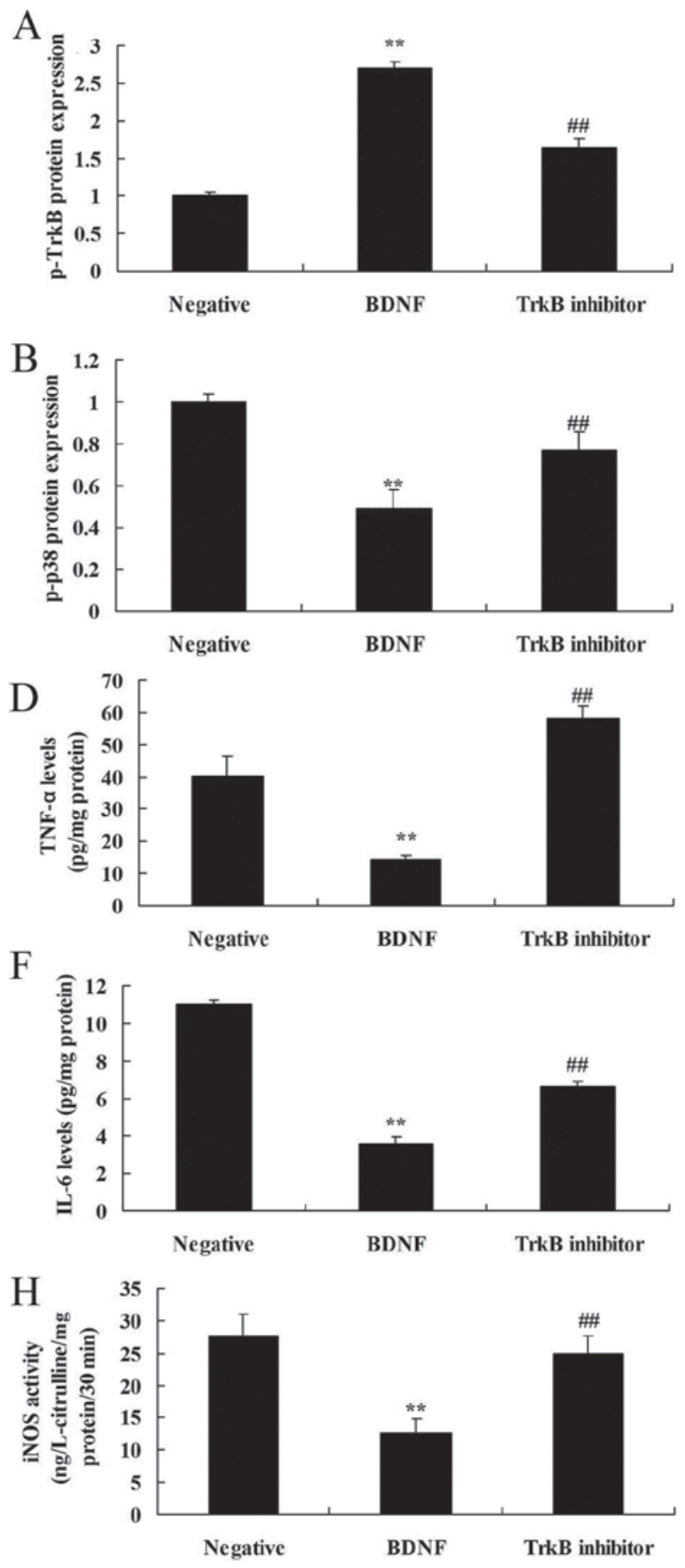

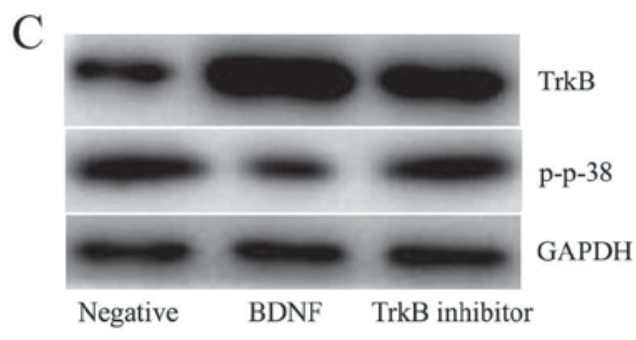

$\mathrm{E}$
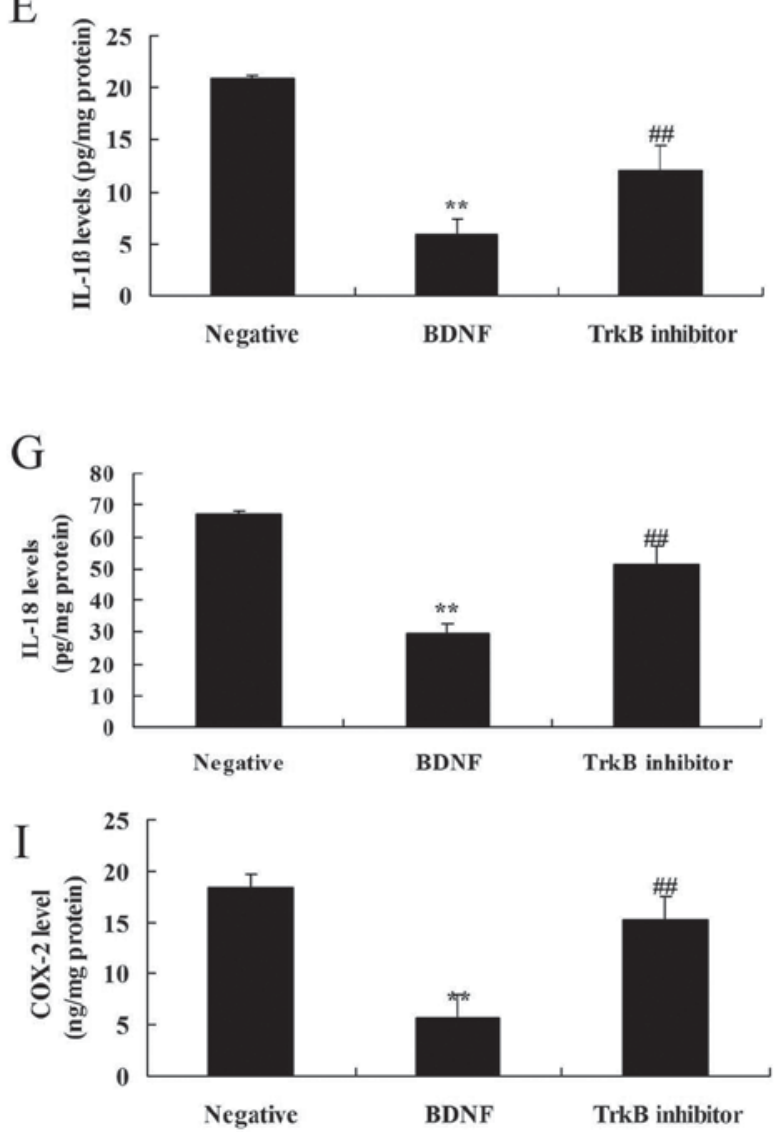

Figure 4. Inhibition of p-TrkB increases the anti-inflammation effects of BDNF on TrkB and p-p-38 protein expressions in vitro. (A) TrkB and (B) p-p-38 protein expression, as determined using statistical analysis, (C) Western blot analysis of BDNF protein expression, (D) TNF- $\alpha$, (E) IL-1 $\beta$, (F) IL-6, (G) IL-18, (H) iNOS and (I) COX2 levels. Negative, negative mimics group; BDNF, Overexpression of BDNF group; TrkB inhibitor, Overexpression of BDNF and TrkB inhibitor group. Data are presented as the mean \pm standard error of the mean for three independent experiments. ${ }^{* *} \mathrm{P}<0.01$ compared with $\mathrm{I}$ group; ${ }^{\# \#} \mathrm{P}<0.01$ compared with II group. TrkB, tyrosine kinase receptor B; BDNF, brain-derived neurotrophic factor; TNF- $\alpha$, tumor necrosis factor- $\alpha$; IL, interleukin; iNOS, inducible nitric oxide synthase; COX2, cyclooxygenase-2.

addition, it may facilitate the recovery of the spinal cord. Previous studies have demonstrated that zinc released from synaptic vesicle has protective effects on ischemic neuron injury (32). Zinc deficiency may lead to death of nerve cells following SCI (32). In the present study, treatment with DHF effectively induced SCI-inhibited TrkB signaling pathway in SCI rats. Han et al (33) suggested that 7,8-DHF prevents onset of psychosis in adult offspring following maternal immune activation via BDNF-TrkB signaling, and demonstrated that DHF reduced inflammation via BDNF-TrkB signaling.

As one member of MAPK family, extracellular signal-regulated kinase is widely prevalent in the central nervous system (34). Following its activation of phosphorylation, extracellular signal-regulated kinase may cause proliferation and activity of microglial cells, and also secrete cytokines 

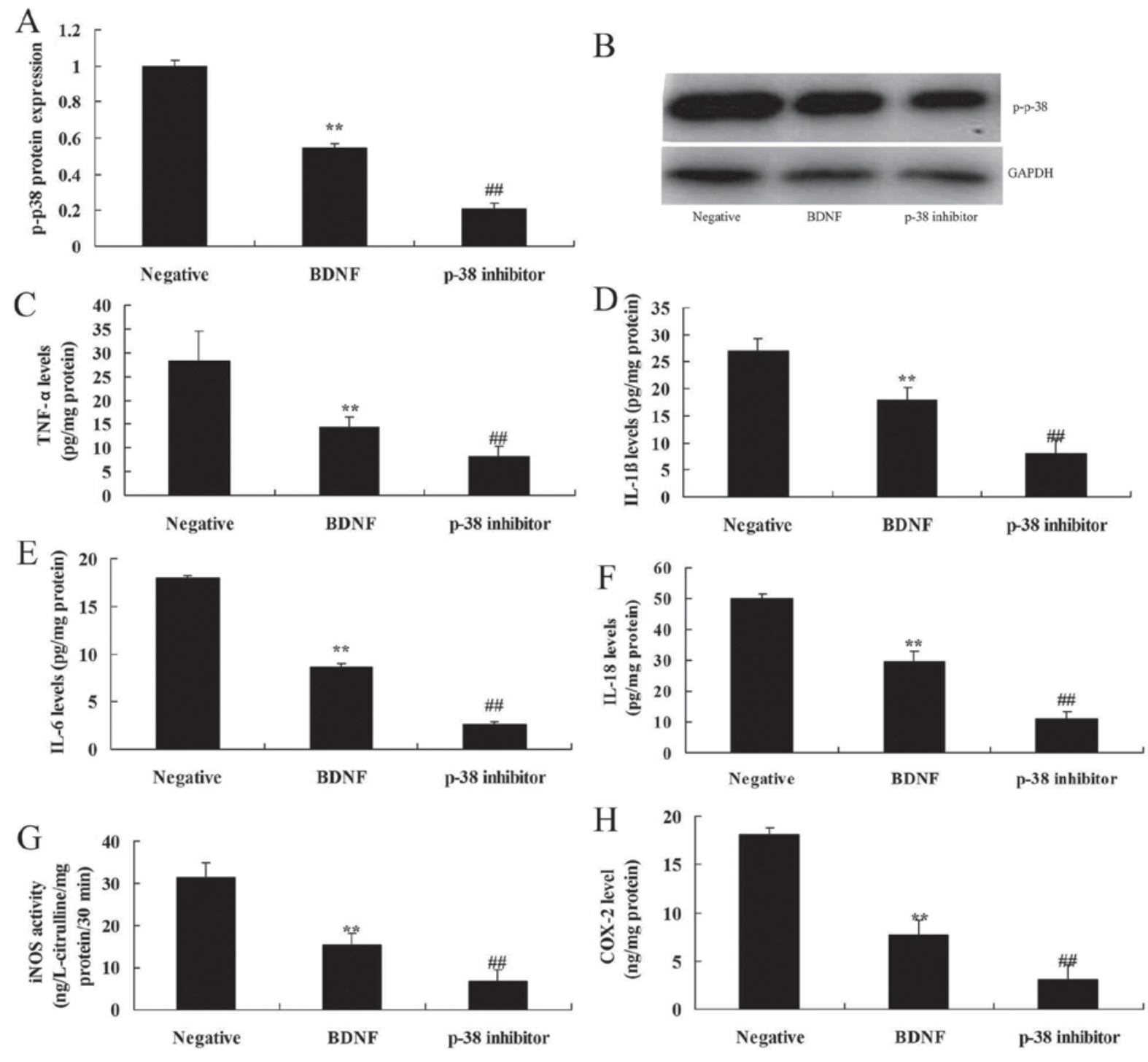

Figure 5. Inhibition of p38 increases the anti-inflammation effects of BDNF on inflammation in vitro. p-p-38 protein expression (A) using statistical analysis, (B) Western blot analysis of BDNF protein expression, (C) TNF- $\alpha$, (D) IL-1 $\beta$, (E) IL-6, (F) IL-18, (G) iNOS and (H) COX2 levels. Negative, negative mimics group; BDNF, Overexpression of BDNF group; p-p38 inhibitor, Overexpression of BDNF and p-p38 inhibitor group. Data are presented as the mean + standard error of the mean for three independent experiments. ${ }^{* *} \mathrm{P}<0.01$ compared with I group; ${ }^{\# \#} \mathrm{P}<0.01$ compared with II group. BDNF, brain-derived neurotrophic factor; TNF- $\alpha$, tumor necrosis factor- $\alpha$; IL, interleukin; iNOS, inducible nitric oxide synthase; COX2, cyclooxygenase- 2 .

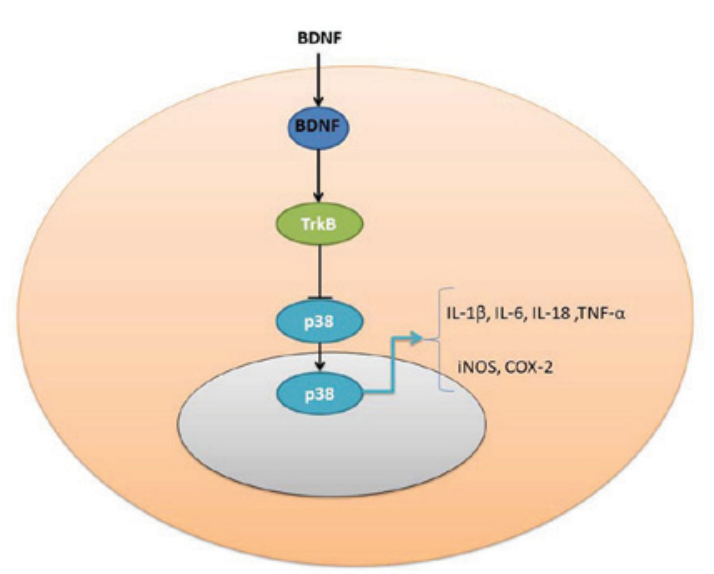

Figure 6. The activation of BDNF reduces inflammation in a spinal cord injury model via TrkB/p38 MAPK signaling. BDNF, brain-derived neurotrophic factor; TrkB, tyrosine kinase receptor B; MAPK, mitogen-activated protein kinase; TNF- $\alpha$, tumor necrosis factor- $\alpha$; IL, interleukin; iNOS, inducible nitric oxide synthase; COX2, cyclooxygenase-2. and TNF, promote inflammatory responses following injuries and eliminate necrotic tissues (34). Inhibition of TrkB or p38 increases the anti-inflammation effects of BDNF on TrkB and p-p-38 protein expression in vitro. Park et al (35) previously reported that 7,8 -DHF attenuates inflammation through the suppression of the nuclear factor- $\kappa \mathrm{B}$ and MAPK signaling pathways. BDNF-TrkB-p38 signaling is an important signaling pathway of treatment with DHF for SCI. In the present study, it was only analyzed whether 7,8-DHF regulates BDNF-TrkB-p38 signaling.

Taken together, the present results indicate that the expression of BDNF was reduced in SCI rats and that the overexpression of BDNF reduces SCI inflammation in vitro through the induction of TrkB and p-p-38 protein expression. Furthermore, the inhibition of TrkB increases the anti-inflammation effects of BDNF on TrkB and p-p-38 protein expression in vitro, which inhibited the effects of BDNF to reduce inflammation in SCI model (Fig. 6). 


\section{Acknowledgements}

Not applicable.

\section{Funding}

The present study was supported in part by grants from the National Natural Science Foundation of China (grant no. 81401014), the Young Scientists Awards Foundation of Shandong Province (grant no. BS2013YY049) and the China Postdoctoral Science Foundation (grant nos. 2012M511036 and 2015T80725).

\section{Availability of data and materials}

The analyzed data sets generated during the study are available from the corresponding author on reasonable request.

\section{Authors' contributions}

JL designed the experiments of the present study; GD and $\mathrm{HH}$ performed the experiments; JL and GD analyzed the data; and JL wrote the manuscript.

\section{Ethics approval and consent to participate}

All animal studies were approved by the Committee of Ethics on Animal Experiments of The First People's Hospital of Three Gorges University (Yichang, China).

\section{Patient consent for publication}

Not applicable.

\section{Competing interests}

The authors declare that they have no competing interests.

\section{References}

1. de Araujo AVL, Barbosa VRN, Galdino GS, Fregni F, Massetti T, Fontes SL, de Oliveira Silva D, da Silva TD, Monteiro CBM, Tonks J and Magalhães FH: Effects of high-frequency transcranial magnetic stimulation on functional performance in individuals with incomplete spinal cord injury: Study protocol for a randomized controlled trial. Trials 18: 522, 2017.

2. Nakashima A, Yamanaka-Tatematsu M, Fujita N, Koizumi K Shima T, Yoshida T, Nikaido T, Okamoto A, Yoshimori T and Saito S: Impaired autophagy by soluble endoglin, under physiological hypoxia in early pregnant period, is involved in poor placentation in preeclampsia. Autophagy 9: 303-316, 2013.

3. Pons J, Huang Y, Arakawa-Hoyt J, Washko D, Takagawa J, Ye J, Grossman W and Su H: VEGF improves survival of mesenchymal stem cells in infarcted hearts. Biochem Biophys Res Commun 376: 419-422, 2008.

4. Tsuzuki T, Okada H, Cho H, Tsuji S, Nishigaki A, Yasuda K and Kanzaki H: Hypoxic stress simultaneously stimulates vascular endothelial growth factor via hypoxia-inducible factor-1 $\alpha$ and inhibits stromal cell-derived factor- 1 in human endometrial stromal cells. Hum Reprod 27: 523-530, 2012.

5. Ottosen LD, Hindkaer J, Husth M, Petersen DE, Kirk J and Ingerslev HJ: Observations on intrauterine oxygen tension measured by fibre-optic microsensors. Reprod Biomed Online 13: 380-385, 2006

6. Kuhn NZ and Tuan RS: Regulation of stemness and stem cell niche of mesenchymal stem cells: Implications in tumorigenesis and metastasis. J Cell Physiol 222: 268-277, 2010.
7. Kato K: Stem cells in human normal endometrium and endometrial cancer cells: Characterization of side population cells. Kaohsiung J Med Sci 28: 63-71, 2012.

8. Schwab KE, Hutchinson P and Gargett CE: Identification of surface markers for prospective isolation of human endometrial stromal colony-forming cells. Hum Reprod 23: 934-943, 2008.

9. Miernik K and Karasinski J: Porcine uterus contains a population of mesenchymal stem cells. Reproduction 143: 203-209, 2012.

10. Zhang L, Xiong W, Xiong Y, Liu H, Li N, Du Y and Liu Y: Intracellular Wnt/beta-catenin signaling underlying 17beta-estradiol-induced matrix metalloproteinase 9 expression in human endometriosis. Biol Reprod 94: 70, 2016.

11. Cosar E, Mamillapalli R, Ersoy GS, Cho S, Seifer B and Taylor HS: Serum microRNAs as diagnostic markers of endometriosis: A comprehensive array-based analysis. Fertil Steril 106: 402-409, 2016.

12. Panda H, Pelakh L, Chuang TD, Luo X, Bukulmez O and Chegini N: Endometrial miR-200c is altered during transformation into cancerous states and targets the expression of ZEBs, VEGFA, FLT1, IKK $\beta$, KLF9, and FBLN5. Reprod Sci 19: 786-796, 2012.

13. Furuya M, Masuda H, Hara K, Uchida H, Sato K, Sato S, Asada H, Maruyama T, Yoshimura Y, Katabuchi $\mathrm{H}$, et al: ZEB1 expression is a potential indicator of invasive endometriosis. Acta Obstet Gynecol Scand 96: 1128-1135, 2017.

14. Sanchez AM, Vigano P, Quattrone F, Pagliardini L, Papaleo E, Candiani $M$ and Panina-Bordignon P: The WNT/ $\beta$-catenin signaling pathway and expression of survival promoting genes in luteinized granulosa cells: Endometriosis as a paradigm for a dysregulated apoptosis pathway. Fertil Steril 101: 1688-1696, 2014.

15. Kim SH, Park JG, Lee J, Yang WS, Park GW, Kim HG, Yi YS, Baek KS, Sung NY, Hossen MJ, et al: The dietary flavonoid Kaempferol mediates anti-inflammatory responses via the Src, Syk, IRAK1, and IRAK4 molecular targets. Mediators Inflamm 2015: 904142, 2015.

16. Zhang JC, Yao W and Hashimoto K: Brain-derived neurotrophic factor (BDNF)-TrkB signaling in inflammation-related depression and potential therapeutic targets. Curr Neuropharmacol 14: 721-731, 2016.

17. Livak KJ and Schmittgen TD: Analysis of relative gene expression data using real-time quantitative PCR and the 2(-Delta Delta C(T)) Method. Methods 25: 402-408, 2001.

18. Basso DM, Beattie MS, Bresnahan JC, Anderson DK, Faden AI, Gruner JA, Holford TR, Hsu CY, Noble LJ, Nockels R, et al: MASCIS evaluation of open field locomotor scores: Effects of experience and teamwork on reliability. Multicenter Animal Spinal Cord Injury Study. J Neurotrauma 13: 343-359, 1996.

19. Cindolo L, Chiodini P, Brookman-May S, De Cobelli O, May M, Squillacciotti S, De Nunzio C, Tubaro A, Coman I, Feciche B, et al: Assessing the accuracy and generalizability of the preoperative and postoperative karakiewicz nomograms for renal cell carcinoma: Results from a multicentre European and US study. BJU Int 112: 578-584, 2013.

20. Masuda H, Maruyama T, Gargett CE, Miyazaki K, Matsuzaki Y, Okano H and Tanaka M: Endometrial side population cells: Potential adult stem/progenitor cells in endometrium. Biol Reprod 93: 84, 2015.

21. Siebels M, Rohrmann K, Oberneder R, Stahler M, Haseke N, Beck J, Hofmann R, Kindler M, Kloepfer P and Stief C: A clinical phase I/II trial with the monoclonal antibody cG250 (RENCAREX $(\mathrm{R})$ ) and interferon-alpha-2a in metastatic renal cell carcinoma patients. World J Urol 29: 121-126, 2011.

22. Opper B, Elsner P and Ziemer M: Cutaneous metastasis of renal cell carcinoma. Am J Clin Dermatol 7: 271-272, 2006.

23. Liang W, Guan H, He X, Ke W, Xu L, Liu L, Xiao H and Li Y: Down-regulation of SOSTDC1 promotes thyroid cancer cell proliferation via regulating cyclin A2 and cyclin E2. Oncotarget 6: 31780-31791, 2015.

24. Jhaveri KS, Elmi A, Hosseini-Nik H, Hedgire S, Evans A, Jewett $M$ and Harisinghani M: Predictive value of chemical-shift MRI in distinguishing clear cell renal cell carcinoma from non-clear cell renal cell carcinoma and minimal-fat angiomyolipoma. AJR Am J Roentgenol 205: W79-W86, 2015.

25. Rini BI, Plimack ER, Takagi T, Elson P, Wood LS, Dreicer R, Gilligan T, Garcia J, Zhang Z, Kaouk J, et al: A Phase II study of pazopanib in patients with localized renal cell carcinoma to optimize preservation of renal parenchyma. J Urol 194: 297-303, 2015. 
26. Guo R, Overman M, Chatterjee D, Rashid A, Shroff S, Wang H, Katz MH, Fleming JB, Varadhachary GR, Abbruzzese JL and Wang H: Aberrant expression of p53, p21, cyclin D1, and Bcl2 and their clinicopathological correlation in ampullary adenocarcinoma. Hum Pathol 45: 1015-1023, 2014.

27. Erdem H, Oktay M, Yildirim U, Uzunlar AK and Kayikci MA Expression of AEG-1 and p53 and their clinicopathological significance in malignant lesions of renal cell carcinomas: A microarray study. Pol J Pathol 64: 28-32, 2013.

28. Mishra SK and Crasta JA: An immunohistochemical comparison of P53 and Bcl-2 as apoptotic and MIB1 as proliferative markers in low-grade and high-grade ovarian serous carcinomas. Int J Gynecol Cancer 20: 537-541, 2010.

29. Liu G, Wang T, Wang T, Song J and Zhou Z: Effects of apoptosis-related proteins caspase-3, Bax and Bcl-2 on cerebral ischemia rats. Biomed Rep 1: 861-867, 2013.

30. Chang HA, Wang YH, Tung CS, Yeh CB and Liu YP: 7,8-Dihydroxyflavone, a tropomyosin-kinase related receptor B agonist, produces fast-onset antidepressant-like effects in rats exposed to chronic mild stress. Psychiatry Investig 13: 531-540, 2016.

31. Guo YB, Bao XJ, Xu SB, Zhang XD and Liu HY: Honokiol induces cell cycle arrest and apoptosis via p53 activation in $\mathrm{H} 4$ human neuroglioma cells. Int J Clin Exp Med 8: 7168-7175, 2015.
32. De Giorgi U, Yuan J, Moroni M, Veronese S, Sartore-Bianchi A, Broggini M, Rosti G, Strebhardt K and Ruffini PA: Germ cell tumors overexpress the candidate therapeutic target cyclin B1 independently of p53 function. Int J Biol Markers 30: e275-e281, 2015.

33. Han M, Zhang JC, Yao W, Yang C, Ishima T, Ren Q, Ma M, Dong C, Huang XF and Hashimoto K: Intake of 7,8-dihydroxyflavone during juvenile and adolescent stages prevents onset of psychosis in adult offspring after maternal immune activation. Sci Rep 6: 36087, 2016

34. Zhuang Z, Ye G and Huang B: Kaempferol alleviates the interleukin-1 $\beta$-induced inflammation in rat osteoarthritis chondrocytes via suppression of NF-kB. Med Sci Monit 23: 3925-3931, 2017

35. Park HY, Park C, Hwang HJ, Kim BW, Kim GY, Kim CM, Kim ND and Choi YH: 7,8-Dihydroxyflavone attenuates the release of pro-inflammatory mediators and cytokines in lipopolysaccharide-stimulated BV2 microglial cells through the suppression of the NF- $\kappa \mathrm{B}$ and MAPK signaling pathways. Int J Mol Med 33: 1027-1034, 2014.

This work is licensed under a Creative Commons Attribution-NonCommercial-NoDerivatives 4.0 International (CC BY-NC-ND 4.0) License. 